\title{
Exploring the Role of Brand Equity and R\&D as Drivers of Product Innovation and Market Performance: An Abstract
}

\author{
Nebojsa S. Davcik, Piyush Sharma, and Nicholas Grigoriou
}

\begin{abstract}
This paper investigates the mediating role of product innovation on the effects of brand equity and R\&D investments on firms' market share. We use data from 10,282 households for 1945 food brands consisting of 531 retailers, 1124 small- to medium-sized enterprises (SME) and 290 multinational corporation (MNC) brands. Our results show that the product innovation strategy works best for MNC but only partially for SME and retailers, especially for organic (vs. conventional and functional) brands. We extend the growing research on marketing resources and branding by exploring the antecedents and outcomes of product innovation, using a common theoretical framework, and provide useful managerial implications for improving marketing strategy through product innovation.
\end{abstract}

\footnotetext{
N.S. Davcik

ISCTE Business School, Lisboa, Portugal

e-mail: davcik@live.com

P. Sharma $(\bowtie)$

Curtin University, Bentley, WA, Australia

e-mail: piyush.sharma@curtin.edu.au

N. Grigoriou

Monash University, Subang Jaya, Malaysia

e-mail: nicholas.grigoriou@ monash.edu
} 